\title{
Research on the Synergetic Mechanism Rooted in the Interest Stakeholders of China's Urban Modern Agriculture
}

\author{
Fuping Zhang ${ }^{1}$, Nan Zhou ${ }^{1}$, Xin Wang ${ }^{1}$, Bo Wang ${ }^{1}$, \& Yuneng Du ${ }^{2}$ \\ ${ }^{1}$ The School of Public Affairs, University of Science and Technology of China, China \\ ${ }^{2}$ College of Economics \& Management, Anhui Agricultural University, China \\ Correspondence: Nan Zhou, the School of Public Affairs, University of Science and Technology of China, Hefei, \\ China.E-mail: munan11@mail.ustc.edu.cn
}

Received: June 26, 2013

Accepted: August 26, 2013

Online Published: October 28, 2013

doi:10.5539/ibr.v6n11p67

URL: http://dx.doi.org/10.5539/ibr.v6n11p67

\begin{abstract}
As a part of modern agriculture, urban modern agriculture gains a worldwide focus, and lots of large cities treat urban modern agriculture as development direction. This study use Beijing for instant, discussed the cooperation actuality among the interest stakeholders. Though the analysis of the benefit imbalance, the disorder, nonlinear, diversity, and correlation were found in the current situation. Finally, a few proposals were put forward to the China's urban modern agriculture development.
\end{abstract}

Keywords: urban modern agriculture, interest stakeholders, cooperative phenomena, interest synergetic

\section{Introduction}

\subsection{Background}

How to develop urban modern agriculture is a worldwide focused issue, which attracted lots of attention by agricultural managers and researchers. Started at 1930s, urban modern agriculture first appeared in Japan, Europe and America, and the concept of urban modern agriculture were treated as a research objective after 1980s. In China, Beijing first established its urban modern agriculture development strategy in the beginning of 1990s, and nowadays, $80 \%$ of Chinese large cities have launched and implemented urban modern agriculture development strategy. Beijing's modern agriculture has gained great achievements, and leads the agriculture industry in China. The rudiment of a modern agricultural industry has been built in Beijing. However, some important issue still need further attention, especially the cooperation and benefit distribution, which impact the stability and synergy of the interest stakeholders.

\subsection{Literature Review}

Urban agriculture is highly related with agricultural productivity progress, urban economy development, social evolution, and culture prosperity. The origin of the urban agriculture is the concept of "Metropolitan agriculture" (Ebnezer, 1989). With the world modernization process, the widely usage of science and technology emerged in the agriculture industry, and scale operation, mechanization, intensification, and marketization became the symbols of the agriculture (ACIL Tasman Pty Ltd., 2009). Urban agriculture and modern agriculture merge together with the same characteristics, so that the urban modern agriculture always located at the suburban area or included in the metropolitan economic circle (Bachev, 1996). The driven forces of the urban modern agriculture are mainly related with the high-tech, green ecological, tourism, and export orientation. Mechanization, factorization, and industrialization have promoted the agriculture productivity effect, agricultural product diversification, and the regional ecological environment optimization, which lead to the integration of agriculture, industry and service. The academic circles called this kind of multicultural industry "urban modern agriculture" (Barnet et al., 1995). Nowadays, "urban modern agriculture" not only attracts the world research's attention, but also stimulates the ordinary people's curiosity. The related study on this issue could be summarized from those following aspects:

Economic geography and economics: Scholars in this field argue that urban population aggregation will definitely cause the increase of the resources consumption, especially the agriculture resources (Christpoher, 1992). While the urban modern agriculture activity can upgrade the urban development to a large extent by not only promoting the city running efficiency, but also improving the living environment and comfort level, so that 
the government should highly support the urban modern agriculture development (Conway, 1986; David \& Tim, 2009).

Urbanology and ecology: Scholars in this field argue that there should be some green land and agricultural garden around the metropolis, so that the residents who lived in the crowded city could have space to relax, and those areas could also be an important supplement to the urban development (Fare et al., 1992). When the urban planning is executed, the proportion of the urban land and rural land should be keeping at an appropriate rate, which can not only support the city retain a healthy and efficient development, but also keep supply continuous power to the urban sustainable development (Vnader, 2002). The urban sustainable development cannot retain without agriculture, while the urban modern agriculture can play a positive role in urban biodiversity and environment improvement.

Sociology: Because of the rapid progress of the urbanization, the rural residents are getting closed to the center of the cities, while the farmers comparatively lack of enough knowledge and technology skill, which induce that famers are less competitive compare to the urban residents (Takawira, 2003). Obviously, urban modern agriculture can provide the farmers who flow into the cities important buffer area and channel (Gail \& Mike, 2003), and build the social labor pool (Pablo, 2000; Smith, 1996)

"Stakeholder Theory" initialed as "ST" came from management science, which originated from a kind of cooperation concept prevailed in 1960s. In 1963, Stanford Research Institute firstly created this word "Stakeholder". In 1984 Milton Friedman established the "Stakeholder Theory", and this theory has been started to use in enterprise management. Friedman argue that stakeholder theory refer to the activities of enterprise manager who comprehensively balance the benefit among the stakeholders, who are highly related with the Enterprise production and management behavior especially the business performance. Since then, the "Stakeholder" and "Stakeholder Theory" have been focused by both scholars and also businessmen, and even widely used in many areas like economics, management science, business ethics, legal science, and sociology. Nowadays the "Stakeholder Theory" has become an important economic theory. In this theory, stakeholders are restricted by other economic entity or person, nobody could arbitrarily extent benefit by offend other's interest, only if all the stakeholders cooperate each other and coordinate their benefit distribution.

\section{Definition of Stakeholders in Beijing Urban Modern Agriculture Industry}

Stakeholder refer to the multiple economic benefit relationship exist in the certain institution, organization, environment, and this kind of relationship include direct and indirect form. Regarding to an organization, a stakeholder was supposed as any related individual or group. The agricultural industry now became a crucial factor with big impact to the national welfare and people's livelihood. In Beijing urban modern agriculture system, farmers, consumers, government, and agricultural product processing enterprise, are all closely linked. Although almost all the people in the urban cycle are related with urban modern agriculture, the stakeholders should only be the main part or highly representative organizations. Based on these hypotheses, this study took urban modern agriculture in Beijing as an instant, and focused on the interest stakeholders and their interest synergetic mechanism in China urban modern agriculture industry. Four kinds of stakeholders were defined as "government", "agricultural enterprise", "research institution" and "farmer".

\section{Current Situation of Stakeholder Cooperation in Beijing Urban Modern Agriculture Industry}

In the development of Beijing urban modern agriculture industry system, stakeholders are interactive, and have individual sole benefit objective. The interest demands of stakeholders are always different, which is a kind of interactive game relationship. The core of conflict is the demand of the distribution of resources or benefit, and all of the stakeholders want their resources and benefit maximization. In the following paragraphs, the stakeholder relationships were analyzed in pair.

\subsection{Government and Agricultural Enterprise}

In the development of Beijing urban modern agriculture industry, government will consider the coordinated development of economy, society, culture, environment, and focus on the unity of economic benefit, the social benefit and ecological benefit. While agricultural enterprise is a kind of profit-making organization, the profit and self-interest is the starting point and final objective. The enterprise will choose its business behavior according to utility maximization principle, and to enhance its economic returns and other benefit. These two different objectives sometimes caused problems, for example, the government may over interfere in the enterprise business behavior, or inadequately support.

On one hand, government sometimes push the agricultural enterprise provide price lower than the free market to the farmers, or let the agriculture enterprise to take excessive social burden. These government behaviors could 
badly influence the business of agricultural enterprise, and make the enterprise suffer losses, which may damage the government credibility and the development of Beijing urban modern agriculture. On the other hand, the duty that needs government attention sometimes hasn't accomplished well, because of the nonstandard government decision-making process or democratic supervision procedures. In addition, the high tax, land occupancy charge, and incidentals impel the risen of the agriculture enterprise running cost, which is negative to the agriculture enterprise competitiveness. Obviously, the government should improve its work in Beijing urban modern agriculture development.

\subsection{Government and Farmers}

For a longtime, Beijing municipal government have paid high attention to the agriculture investment, and farmer support. The municipal government adhere to provide financial subside, price support, tax deduction, education coverage, social insurance, and infrastructure construction. However, from a practical perspective, some problem still exits like less investment, too much restriction and insufficient service. The farmers in the remote mountainous area still cannot get enough help, and in statistic the proportion is around $30 \%$.

In the aspect of agricultural land use, the communication between government and farmer is not sufficient, the option right, right to know, participation rights are ignored. The land use property of famer often encroached or deprived, and toll breakdown sometimes happen, which arouse farmers' strong resistance. These wrong behaviors of government are negative to the Beijing urban modern agriculture. While as the main subject of agriculture industry, farmers' interest demand embody in the agriculture land output and government subsidy. When farmers feel their self-interest space is threatened or violated, they will preserve the rights through applying for an audience with the higher authorities to appeal for help, or even confront the municipal government. However, based on self-interest, the famers will spontaneously discover rural resources and infrastructure construction, and because of organize insufficiency, these discoveries belong to extensive growth, destructive exploitation, and ruined the agricultural resources and ecological environment.

\subsection{Government and Research Institution}

Problems also exist in the relation of government and research institution. First issue is scientific research funding problem. Agricultural research institution always service the weak industry, who always lack fund, and government support to the agricultural research institutions sometimes not enough. So that agricultural research institution constantly supplies free service to the farmers, which induce the motivation shortage and discontinuity of guidance. Second issue is policy environment and policy system problem. Recently, the Beijing municipal government successively issued a few documents in talent cultivation, science and technology investment, technology project support, but the documents and regulation in finance, taxation, land, and credit are imperfect. For example, the policy support in children of migrant workers in cities, poor agricultural students allowance, and new type farmers are not strong enough. In the aspect of new rural practical scientific research projects, there still exists lack protection of intellectual property, technology consulting, and capital assess evaluation, these problems hinder the agricultural science and technology achievements transformation of continuous development.

\subsection{Agricultural Enterprise and Farmers}

Agricultural Enterprise and Farmers are both individual stakeholders in the market economy system, and they both operate their business according to the criteria that maximize their benefits. In order to acquire high quality raw material and decrease the transaction cost, the enterprise initiatively establish agricultural trade relationship with the farmers. The forms of cooperation can be transfer profit from agricultural enterprise to farmers, serving the farmers freely, purchasing agricultural products at protected prices, or dividing the net income according the contact.

However in the benefit distribution aspect, agricultural enterprise and farmers are unequal in economic and social status, the benefit connection mechanism between the standardization and institutionalization is not strong enough. Firstly, to the agricultural enterprise, they will support the famers only if their business will not be negatively influenced and get enough profit. Secondly, the enterprise-style management and traditional tillage method are conflicting, so that traditional farmers are hard to reach the demand of the agricultural enterprise, and also hardly to share the value-added profits. Only use the cooperative economic organization, famers can improve the bargaining position and defend the risk of the market. In addition some agricultural enterprises sometimes make unfair contracts to farmers, and meanwhile some farmers also make malicious breach of contract, or both of them fail to fulfill the contract, which are harmful to both sides. Furthermore, agricultural enterprises sometimes ruin the local ecosystem and environment, and farmers always became the sufferer of this kind of damage. 


\subsection{Agricultural Enterprise and Research Institution}

The curial contradiction in agricultural enterprise and research institution is imbalance between supply and demand. Firstly, from the positive perspective, research institution inclines to cooperate with the agricultural enterprise in order to seek the high added value brought by scientific and technological achievements. While the cooperation of agricultural enterprise and research institutions neither can raise the economic benefit in short while, nor can gain fund support or tax deduction, so that agricultural enterprise always reluctant to be involved in the cooperation. From the demand and supply of scientific achievements perspective, the research activities are not driven by the market economy, cannot provide practical, proper, low risk, high efficient scientific achievement, so that the achievement conversion rate is low. In order to reduce R\&D investment, agricultural enterprises generally incline to buy the scientific achievement directly but not to cooperate, and the reason is the payment that enterprise willing to pay always much lower than the research institutions' expect. In addition, from technical reliability and controllability perspective, research institutions prefer self-develop scientific achievement compare to cooperation, and totally get the future profit. With regard to the sized enterprises, those companies have self-ability to do $R \& D$, which induce the reluctant cooperation with research institutions. In the meanwhile, some small scale, low powerful companies incline to introduce mature "Market-oriented products", so they usually don't willing to fulfill the commercialization of research findings, and also cannot afford. Finally, in demand and supply of agriculture scientific-technology talents, the shortage of professional stuff become more and more serious, to the contrary, the graduates in colleges and universities is hard to find jobs they want. Influenced by the old system and opinion, the service consciousness of research institutions is not strong, and agricultural science and technology talent cultivation system cannot meet the need of the reality. In the other hand, the fresh graduates job choosing concept are not mature, some of them despise the rural and agricultural work, and lack of practical experience.

\subsection{Research Institutions and Famers}

With the rapid development of Beijing modern agriculture, the market awareness and right consciousness of farmers have been enhanced. Simultaneously, with the benefit expression channel became completed, the famers are eager to personalized, diversified services, and service content requires universality and hierarchy. However, research institutions are hard to meet the needs of Beijing suburb farmers in diversity of agricultural modernization and information-based services, so that supply gap of education, science and technology, and talents became even bigger and bigger.

From the aspect of service coverage proportion, nowadays, there are still $30 \%$ of the farmers cannot get relevant agricultural science and technology supporting services in Beijing. The ways that farmers obtain information mainly rely on old media like oral spreading and light box advertising, and only $20 \%$ famers use modern methods to acquire information. From the data released by the local government, only $80 \%$ villages in Beijing still haven't established science and technology service stations. In the civil servants aspect, the current number of rural civil servants are not enough and unstable, and generally the personnel qualification and professional title are generally low, which cannot meet the demand of famers. In addition, research institutions haven't provide timely technic help, and lack of supporting service skills. Actually, the talents trained by the research institutions always flow into the urban not rural areas, and farmers haven't sufficient channel to promote their technic skill, so the gap between the research institutions and famers became even bigger.

\section{Problems Analysis of Stakeholders in Beijing Urban Modern Agriculture Industry}

In terms of cooperation actuality about stakeholders in Beijing urban modern agriculture industry mentioned in previous chapter, noteworthy is the fact that the cooperation among stakeholders show at least four traits, such as disorder, nonlinearity, diversity and correlation.

\subsection{Disorder}

Although these interacted and interdependent stakeholders in urban modern agriculture industry constitute the system of urban modern agriculture industry, they don't belong to this system absolutely, but participating in it due to other interest demands and conditions. From the horizontal perspective, all kinds of stakeholders possess complexity, messy and disordered demands, nonidentity interests of all elements, and they can't substitute with each other, even the opposite; from the longitudinal perspective, with the development of urban modern agriculture industry, these stakeholders having different standpoints and thoughts show varying interests and viewing angles. For instance, if the perspectives change, the entire interest-chain of the system in the urban modern agriculture industry can also modify. Therefore, the operating circumstance of the urban modern agriculture industry displays uncertainty and disorder to some extent. 


\subsection{Nonlinearity}

The construction of the urban modern agriculture industry not only value long-term interests, but current interests; not only economic benefits, but social interests; not only the overall interests, but the individual efficiencies. The developing process is viewed as dynamic and fickle. Therefore, the connection and influence among all the stakeholders are nonlinear. The function, target and effect of these stakeholders in the urban modern agriculture industry are entirely different and irreplaceable. The behaviors as well as their models are all influenced by others. Under the condition of the uncertainty and pursuing their own maximal interests, the inconformity of the interest disparity and the objective function of these stakeholders give rise to a more conspicuous complexity and nonlinearity among all the stakeholders. Not only can the nonlinear effect bring the positive effect for the urban modern agriculture industry, but also the negative effect which can be thought massive and long term.

\subsection{Diversity}

The construction for the urban modern agriculture industry involves different stakeholders, such as government, agricultural enterprise, research institution as well as farmers; the combination with the arrangement, economy, society and marketing philosophy; the connection of policy, raising capital, circulation and issues of agriculture, farmer and rural area. Multiple interest demands and conflicts are generated due to various positions, ideas and dynamic changes on stakeholders.

\subsection{Correlation}

Interest demands among stakeholders demonstrate diverse. Because these stakeholders are the important factor in the system of the urban modern agriculture industry, their interest demands display relevance (even the coherence). When the interest conflicts occur, they can perform the correlation in the interest game. As a result, the relationships among the stakeholders transfer unceasingly.

\section{Conclusions}

The interests among stakeholders in the development of urban modern agriculture industry are inconsistent. Their relationships are a kind of interaction and game. The essence of conflict can be thought an interest demand for resources division and renewal distributions. Each one strive for a further optimization about resources quantity and structure of their own. The urban modern agriculture industry of Beijing includes four stakeholders, which are government, agricultural enterprise, research institution and farmers. The condition of their cooperation affects the development of Beijing's urban modern agriculture industry. At present, there exists imbalance in the aspect of synergetic relationship and interest distribution among all the stakeholders in the urban modern agriculture industry of China. In the system of the entire urban modern agriculture industry, they represent disorder, nonlinearity, diversity and correlation. These problems should be paid more attention.

As promoting the urban modern agriculture industry, it is pressing to coordinate the relationship among stakeholders to guarantee their synergetic, high efficient, well-organized and reasonable development Only by establishing a kind of synergetic developing system, ensuring its normal and steady operating, obtaining relevant balance through repeating games among stakeholders, can we maintain harmonious and healthy development situation.

Though the paper finds and summarizes the problems with respect to the development of the urban modern agriculture industry in order to provide some reference experience, deep synergetic analysis about stakeholders are not launched. In the future researches, on one hand, we should make a further investigation to acquire more abundant materials; on the other hand, we need to measure the synergy of concrete stakeholders to construct effective solving models by using some quantitative methods.

\section{References}

ACIL Tasman. (2009). Agriculture and GHG mitigation Policy: options in addition to the CPRS. Report for Victorian Department of Primary Industries and Industry and Investment NSW.

Bachev, H. (2004). Efficiency of agrarian organizations. Available at SSRN 903483. http://dx.doi.org/10.2139/ssrn.903483

Barnet, V., Johnston, A. E., Landau, S., et al. (1995). Sustainability: the Rothamsted experience. In Barbett, V. R., \& Steiner, R. (Eds.), Agricultural Sustainability: Economic, Environmental and Statistical Considerations (pp. 171-206). Chichester, UK: Wiley.

Christpoher, R. B., \& Thomas, R. R. J. (1992). Agriculture in the city's countryside. London: Belhaven Press. 
Conway, G. R. (1986). Agroecosystem analysis for research and development. Bangkok: Winrock International.

David, B., \& Tim, J. (2009). Greenhouse Gas Reduction Policies and Agriculture: Implications for Production Incentives and International Trade Disciplines. ICTSD-IPC Platform on Climate Change, Agriculture and Trade, August.

Ebenezer, H. (1984). Garden cities of tomorrow. Harvard University Press.

Fare, R., Grosskopf, S., Linderdgren, B., et al. (1992). Productivity changes in Swedish pharmacies 1980-1989: A nonparametric Malmquist approach. Journal of Productivity Analysis, 3(1/2), 85-101. http://dx.doi.org/10.1016/0925-5273(94)00063-G

Gail, S., \& Mike, M. (2003). Facilitating land access for the Copperbelt's periurban farmers. Urban Agriculture Magzanie, 1, 34-36.

Pablo, T. L. (2000). Mexico City: the integration of urban agriculture to contain urban sprawl. In Bakker, N., Dubbeling, M., Gündel, S., Sabel-Koschella, U., \& Zeeuw, H. (Eds.), Growing cities. Growing Food. Eurasburg: Proff Offsetdruck.

Smith, P., Martino, D., Cai, Z., Gwary, D., Jan-zen, H., Kumar, P., MeCarl, B., Ogle, S., Ogle, F., Mara, C., Rice, B., Scholes, O. (2007). Agriculture. Climate Change: Mitigation. Contribution of working Group to the Fourth Assessment Report of IPCC. Cambridge, UK \& New York, NY: Cambridge University Press.

Takawira, M., Shingirayi, M., \& Rene, V. V. (2003). Availabity, access and usability of land for urban agriculture. Agriculture Magzanie, 1, 1-3.

Hayo, M. G. van der W., \& Jean, P. (2002). Evaluation of the environmental impact of agriculture at the farm level: a comparison and analysis of 12 indicator-based methods. Agriculture, Ecosystems and Environments, 93, 131-145. http://dx.doi.org/10.1016/S0167-8809(01)00354-1

\section{Copyrights}

Copyright for this article is retained by the author(s), with first publication rights granted to the journal.

This is an open-access article distributed under the terms and conditions of the Creative Commons Attribution license (http://creativecommons.org/licenses/by/3.0/). 